This item was submitted to Loughborough's Research Repository by the author.

Items in Figshare are protected by copyright, with all rights reserved, unless otherwise indicated.

\title{
The applicability of Lumped Parameter modelling in houses using in-situ measurements
}

\section{PLEASE CITE THE PUBLISHED VERSION}

https://doi.org/10.1016/j.enbuild.2020.110068

\section{PUBLISHER}

Elsevier

\section{VERSION}

AM (Accepted Manuscript)

\section{PUBLISHER STATEMENT}

This paper was accepted for publication in the journal Energy and Buildings and the definitive published version is available at https://doi.org/10.1016/j.enbuild.2020.110068.

\section{LICENCE}

CC BY-NC-ND 4.0

\section{REPOSITORY RECORD}

Dimitriou, Vanda, Steven Firth, Tarek Hassan, and Tom Kane. 2020. "The Applicability of Lumped Parameter Modelling in Houses Using In-situ Measurements". Loughborough University. https://hdl.handle.net/2134/12180735.v1. 


\section{The applicability of Lumped Parameter modelling in houses using} in-situ measurements

School of Architecture, Building and Civil Engineering, LE11 3TU, Loughborough University,

6 Declarations of interest: none

\section{$7 \quad$ Abstract}

8 The Lumped Parameter technique is a simplified thermal modelling method, which can be informed by measured operational data whilst allowing for physical interpretation of components and

10 processes. The application of Lumped Parameter methods to the residential sector has been limited,

11 primarily due to the lack of availability of operational data and the complex nature of real-world

12 factors, such as variable occupant behaviours. This work investigates the potential of using the

13 Lumped Parameter technique for modelling the performance of existing houses using high

14 resolution in-situ measurements. Lumped Parameter models are created based on building surveys

15 of eleven existing domestic buildings in the UK. The models are shown to have an average Root

16 Mean Square Error (RMSE) of $1.35^{\circ} \mathrm{C}$ when compared to measured values of internal air

17 temperature. A parametric analysis of model parameters showed wall thermal resistance, window

18 area, boiler efficiency and infiltration rate as the most significant factors affecting the indoor air

19 temperature calculated values. Model calibration improved the average RMSE to $1.03^{\circ} \mathrm{C}$ (a $23.7 \%$

20 decrease from initial fit). In conclusion, the Lumped Parameter models were able to realistically

21 represent the majority of the houses, highlighting the technique's potential in informing strategic

22 retrofit decision making across the housing stock.

\footnotetext{
* Corresponding author. E-mail address: v.dimitriou@lboro.ac.uk, Tel.: +44 1509223439

${ }^{1}$ E-mail address: s.k.firth@lboro.ac.uk

${ }^{2}$ E-mail address: t.hassan@1boro.ac.uk

${ }^{3}$ E-mail address: t.kane@,lboro.ac.uk
} 


\section{Keywords}

24 In-situ data; domestic buildings; lumped parameter models; grey-box modelling; hybrid modelling

\section{Introduction}

26 The Lumped Parameter modelling technique, also commonly referred to as Resistance Capacitance

27 (RC) modelling or thermal networks, is the dominant building representation method in simplified

28 dynamic thermal analyses. It has been identified as the most common model for building load

29 prediction, with applications in on-line building optimal control and demand response [1] with some

30 of the earliest studies using this technique appearing in the 1970s [2]. The Lumped Parameter

31 modelling technique is based on the electrical equivalency of Resistances and Capacitances of the

32 thermal networks [3] to represent the building system. It forms the basis of the simplified hourly

33 method used by BS EN ISO 52016-1:2017 [4] for calculating the energy use for space heating and

34 cooling.

35 The Lumped Parameter technique can be used as a grey-box model, a hybrid model combining the

36 advantages of data-driven and physical modelling. Grey-box models have been found to provide

37 increased accuracy when compared to both black-box (purely data-driven) and white-box (forward)

38 models [5]. Grey-box and, therefore, Lumped Parameter modelling, is informed by operational data

39 from the building, whilst being interpretable from a building physics perspective. As such, the

40 technique is appropriate for use with in-situ measurements, allowing for direct link between the

41 model variables and the building's physical components and between the modelling processes and

42 real heat flows [6].

43 Lumped Parameter modelling has certain advantages. When compared to more advanced modelling

44 techniques (such as finite difference or response factor used in building simulation software), it

45 requires less detailed model inputs, which is useful for cases where many model inputs are unknown

46 or hard to collect, as is the case in existing buildings (see [7]). When compared to steady state

47 modelling producing monthly results, it provides a simple and comprehensive method for dynamic 
thermal modelling and refined building performance output at sub-hourly intervals [8]. The equation-based models can be developed by researchers in their preferred coding language (e.g. using Python or Modelica), which makes them ideal as a prototyping tool and for initial testing of new techniques and building technologies (see [9] and [10]). As the models are much simpler in nature, they run fast, which is useful when a large number of simulation runs are required, as is the case in an optimisation study or a study modelling a large number of buildings at city-scale (see [11]). Finally, the flexibility of the model equations allows to undertake 'inverse' modelling enabling the use of different combinations of input datasets. For example, instead of defining temperature setpoints to calculate energy consumption, using energy consumption measurements to calculate internal temperatures (see [12]).

\subsection{Previous work using the Lumped Parameter modelling technique for building representation}

60 Lumped Parameter modelling is a well-established methodology for dynamic heat transfer representation of buildings. In the following paragraphs a review of a selection of studies exploring the progression of applications of the Lumped Parameter technique in buildings, since some of the earliest and up to the most recent studies, is provided. More information on the theoretical

64 background of the technique is also available ([13], [14]).

65 Some of the earliest studies [15] explored low order Lumped Parameter models in various classical problems, providing some of the earliest proofs of the adequacy of the technique in analysing the behaviour of buildings. Further research built on these findings: expanding to higher order models and including additional model inputs (such as solar radiation and occupancy) ([16] [17] [18]); validating the model with multiple tests on a theoretical, analytical and empirical level through

70 comparison of results with analytical calculations and measured operational data [19]; and

71 confirming that by using half-hourly observations of the building's thermal response, the model

72 parameters could be identified, although some of the parameter values varied significantly from 73 their expected values ([20], [21]). 
74 With the increasing uptake of information technology, research work explored more viable

75 parameter estimation procedures, using linearised models and simplified parameter estimation 76 algorithms, easily applicable to Building Energy Management Systems [22]. More advanced and 77 specialised applications started to appear, such as WinSim [23], a software based on the Lumped 78 Parameter technique, developed to evaluate the effect that the window system has on the building's 79 thermal environment.

80 Other applications of the Lumped parameter modelling technique at a whole building level include:

81 hybrid applications, exploring different building model representation, combining the Lumped 82 Parameter methodology with detailed physical modelling, such as Conduction Transfer Function 83 [6]; multizonal applications, assessing the adequacy of the technique when applied to multiple 84 zones of a building [24]; and applications in alternative building types, such as thermally activated 85 buildings, with heating systems incorporated into their structure (e.g. underfloor heating) [25]. At 86 the same time, a number of studies focusing on the Lumped Parameter technique narrowed down 87 their scope from a whole building level to specific building components, such as external walls $88 \quad([26],[27],[28],[29])$

89 One of the main challenges when using the Lumped Parameter technique for building 90 representation, is identifying suitable model architectures that can accurately capture heat 91 dynamics, whilst maintaining relative model simplicity and a low computational cost. The research 92 community has been active in this research area, with studies exploring model complexity to 93 identify important parameters for building system representation ([30], [31], [32]). Despite current 94 advances in computational power and the ability to accommodate increasing model complexities, 95 low order models have proved adequate for building representation, with some of the most recent 96 applications maintaining focus on simpler model architectures ([33], [34]).

\section{$97 \quad 1.2$ Originality of this work}

98 The originality of the research reported here is the focus on real-life, existing, occupied houses, 99 when investigating the Lumped Parameter technique's applicability. Lumped Parameter modelling 
is a technique that has found multiple applications in previous work and is considered an established

101 methodology for building representation. However, in the past, the applicability of the Lumped

102 Parameter modelling technique could not be extensively explored in the domestic context, due to

103 the lack of sensor data from existing domestic building environments, the high variability in 104 domestic occupancy patterns and the complexity implied when compared to non-residential or 105 controlled environments. Previous work on Lumped Parameter modelling has primarily focused on 106 the non-residential sector, controlled experimental buildings and simulations to evaluate the 107 applicability of the technique. Most of the studies focus on non-residential buildings, such as 108 schools and blocks of offices, and experimental buildings ([6], [16], [19], [20], [22], [35], [27]). 109 With simulation software increasing both in capabilities and popularity, more recent studies have 110 resorted to simulated data for model comparison and validation ([36], [37], [24], [38], [39], [40]).

111 Some work has studied the residential sector, however, either the selected houses have been 112 unoccupied, leading to unrealistic representations of the actual conditions, or the results relevant to 113 domestic buildings have been merged with results from non-residential or controlled environments 114 or, in cases, not discussed at all ([17], [41], [31], [32]). In a recent review of data-driven building 115 energy consumption prediction models [42] it was found that only $19 \%$ of the studies focused on 116 houses, with the majority of previous work focusing on non-domestic buildings. The study 117 concluded that focusing on data-driven, and in particular grey-box, methods for the residential 118 buildings is imperative in view of the imminent data availability from in-home sensors and the 119 potential savings that could arise from successfully informing policy strategies. This statement is 120 further supported by the latest published statistics in which the domestic sector is shown as the 121 second most energy intensive sector after transport, accounting for $28 \%$ of total energy use in the 122 UK in 2017 [43].

123 Summarising the findings from the review presented above, $77 \%$ of previous studies used non124 residential, controlled, experimental buildings and simulations to explore the applicability of the 125 Lumped Parameter technique in buildings. The remaining 23\% of studies that considered domestic 
126 properties, presented results that were not directly attributable to real-life homes, highlighting the

127 gap in research offering clear insights into one of the most energy and $\mathrm{CO}_{2}$ intensive sectors, the

128 domestic sector. The aim of the research reported here was to investigate the potential of the Lumped

129 Parameter modelling technique in representing existing houses. A three-node, 2nd order Lumped

130 Parameter model was selected as a well-researched model for building representation in previous

131 studies of non-domestic and experimental buildings. Individual models were created for a sample of

13211 domestic buildings in the UK, studied as part of a wider UK Government funded project into the

133 Smart Home concept [44]. The local weather data, whole-house gas and electricity consumption and

134 internal air temperatures recorded over an 8-week time period were used for model validation and

135 calibration. The focus was on the heating season, as heating accounts for most of the fuel consumed

136 in UK domestic buildings. The applicability of the Lumped Parameter modelling technique during

137 unheated seasons was out of the scope of this paper.

138 The three stages of this study were:

139 - Initial model development and validation (section 6.1): Lumped Parameter Models were

140 constructed using analytical methods, building information gathered from building surveys and

141 occupant questionnaires. The models were run using the local weather data and the recorded

142 gas and electricity consumption as model inputs. The models were then validated through

143 comparison of calculated versus measured internal air temperatures.

144 - Parametric analysis (section 6.2): To determine which of the model parameters (e.g. wall

145 thermal resistance, window size, boiler efficiency) had the greatest influence on the model

146 output.

147 - Model calibration to the measured data (section 6.3): Based on the results of the validation and 148 the parametric analysis, the most impactful model parameters were altered to determine the best 149 fit of the model outputs to the measured data. The effect on the model parameter values of $150 \quad$ calibrating the models using in-situ data was assessed. 
151 The methods used and the main findings on the applicability of the Lumped Parameter technique 152 to model the internal temperatures of existing domestic buildings are presented and discussed in the 153 following sections.

\section{$154 \quad 2$ The selected Lumped Parameter model}

155 Based on model architectures from previous work, a 3-Resistance, 2-Capacitance (3R2C) model 156 was selected to represent the heat transfer flows and temperatures in the buildings (Figure 1). The 157 simple two-time constant model has found multiple applications in explorations of the Lumped 158 Parameter technique for building representation over the years and, although alternative model 159 structures have been explored, the two-time constant model is still identified as one of the most 160 popular for building representation ([15], [16], [19], [20], [22], [23], [37], [31], [40], [34], [33]).

161 The model has three nodes: i) 'node i' which is the indoor air node representing the building indoor 162 air and internal mass (including internal partitions and furniture) as a single node with temperature 163 ' $\mathrm{T}_{\mathrm{i}}$ ' and thermal capacity ' $\mathrm{C}_{\mathrm{i}}$ '; ii) 'node $\mathrm{e}$ ' which is the building envelope node representing all 164 external walls, roofs and floors with temperature ' $\mathrm{T}_{\mathrm{e}}$ ' and thermal capacitance ' $\mathrm{C}_{\mathrm{e}}$ '; and iii) 'node 165 a' which is the external air node representing the external climate with temperature ' $\mathrm{T}_{\mathrm{a}}$ ' (this node 166 represents the boundary conditions and has no capacitance). The three resistances of the model are:

167 i) the thermal resistance ' $R_{\mathrm{ie}}$ ' $(\mathrm{K} / \mathrm{W})$ between the indoor air node and the building envelope node; 168 ii) the thermal resistance ' $R_{\text {ea }}$ ' $(\mathrm{K} / \mathrm{W})$ between the building envelope node and the external 169 temperature node; iii) the thermal resistance ' $\mathrm{R}_{\mathrm{ia}}$ ' $(\mathrm{K} / \mathrm{W})$ between the indoor air node and the 170 external air node of the building elements with no inertia (i.e. windows and doors). A single node 171 representation for the building envelope has been selected as the simplest feasible building envelope 172 representation. The two envelope resistances ' $R_{\mathrm{ie}}$ ' and ' $\mathrm{R}_{\mathrm{ea}}$ ' directly relate to the total envelope 173 resistance ' $\mathrm{R}_{\mathrm{e}}$ ' and the node positioning which is determined by the value of " '.

174 In addition to the three resistances and two capacitances, there are three model parameters: 'a', the 175 boiler efficiency; ' $\mathrm{A}_{\mathrm{w}}$ ' $\left(\mathrm{m}^{2}\right)$, the window area corrected for frame type, transmittance and 176 orientation, incorporating an adjusting factor for the solar gains to an appropriate angle of incidence; 
and ' $\mathrm{N}$ ' $(\mathrm{ac} / \mathrm{h})$, the number of air changes per hour due to infiltration, which is embedded in ' $\mathrm{Q}_{\mathrm{i}}$ ',

178 the heat loss due to infiltration term.

179 The model has five input variables to account for weather conditions and heat gains to the indoor 180 air node: i) ' $\mathrm{T}_{\mathrm{a}}$ ' $\left({ }^{\circ} \mathrm{C}\right)$, the measured external air temperature; ii) ' $\mathrm{Q}$ ' $(\mathrm{W})$, the measured gas 181 consumption at the meter level assuming that all gas consumption contributes to space heating 182 gains, including gas consumption used for purposes other than space heating, such as Domestic Hot 183 Water and cooking; iii) ' $\mathrm{Q}_{\mathrm{e}}$ ' (W), the measured electricity consumption at the meter level; iv) ' $\mathrm{Q}_{\mathrm{s}}$ ' $184\left(\mathrm{~W} / \mathrm{m}^{2}\right)$, the measured average solar irradiance on the horizontal plane; and $\left.\mathrm{v}\right)$ ' $\mathrm{Q}$ i' $(\mathrm{W})$, the heat 185 loss due to infiltration. The building envelope temperature, ' $\mathrm{T}_{\mathrm{i}}$ ' $\left({ }^{\circ} \mathrm{C}\right)$, is used as the calibration 186 variable, the variable whose measurements need to match with the model predictions.

187 There are two model output variables: the difference between two time steps (dt) in the indoor air 188 temperature, ' $\mathrm{dT}_{\mathrm{i}, \text { pred }}$ ' $\left({ }^{\circ} \mathrm{C}\right)$, which is used for model calibration through comparison with the indoor 189 air ' $\mathrm{T}_{\mathrm{i}}$ ' measurements; and the difference between two time steps (dt) in the envelope temperature, 190 'dT $\mathrm{e}_{\mathrm{e} \text { pred }}\left({ }^{\circ} \mathrm{C}\right)$.

191 The ordinary differential equations describing the heat transfer processes occurring at the indoor 192 air node and at the building envelope node at a whole house level are given below.
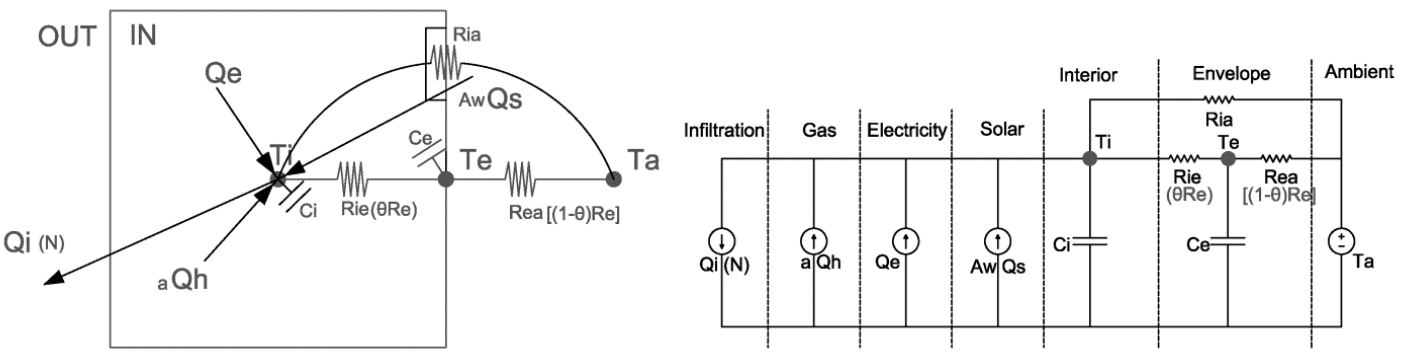

Figure $1 \mathrm{~T}_{\mathrm{i}} \mathrm{T}_{\mathrm{e}} \mathrm{T}_{\mathrm{a}}$ lumped parameter model with $\mathrm{Q}_{\mathrm{h}}, \mathrm{Q}_{\mathrm{s}}, \mathrm{Q}_{\mathrm{e}}$ and $\mathrm{Q}_{\mathrm{i}}$ at the $\mathrm{T}_{\mathrm{i}}$ node. A two-dimensional representation of the lumped parameter model (left) and the electrical analogy (right)

$$
\begin{gathered}
d T_{i, p r e d}=\left[\frac{\left(T_{e}-T_{i}\right)}{C_{i} R_{i e}}+\frac{\left(T_{a}-T_{i}\right)}{C_{i} R_{i a}}+\frac{\mathrm{a} Q_{h}}{C_{i}}+\frac{Q_{e}}{C_{i}}+\frac{\mathrm{A}_{\mathrm{w}} Q_{s}}{C_{i}}+\frac{Q_{i}}{C_{i}}\right] d t \\
d T_{e, p r e d}=\left[\frac{\left(T_{i}-T_{\mathrm{e}}\right)}{C_{e} R_{i e}}+\frac{\left(T_{a}-T_{e}\right)}{C_{e} R_{e a}}\right] d t
\end{gathered}
$$




\section{In-situ data}

197 The building survey data and high-resolution operational data were collected through a Research

198 Council's UK collaborative project [45] [44]. Monitored data from eleven homes collected over an

199 8-week time-period during the heating season of 2014 were used for this work.

\section{$200 \quad 3.1$ Building survey data}

201 Table 1 shows a summary of the building characteristics for the building sample used. The sample

202 of the eleven houses, was dominated by detached dwellings with high floor areas, $\left(128 \mathrm{~m}^{2}\right.$ on

203 average), which is significantly higher than the national average floor area of $94 \mathrm{~m}^{2}$ [46]. As the

204 house sample is dominated by older detached dwellings, high overall thermal capacitances and high

205 envelope heat losses were expected. All homes were heated with gas-fired boilers, supplying hot

206 water to wall-mounted room radiators. For the boiler efficiencies the Building Research

207 Establishment's Product Characteristics Database was used. The efficiencies ranged from an

208 estimated 0.910 in the most efficient boiler of House 4 to 0.650 in the least efficient boiler of House

2098 , with average boiler efficiency across the eleven houses of 0.836 . The secondary heating systems

210 have been also reported where applicable.

\begin{tabular}{|c|c|c|c|c|c|c|c|}
\hline $\begin{array}{c}\text { House } \\
\text { number }\end{array}$ & House type & Construction type & $\begin{array}{c}\text { Construction } \\
\text { age }\end{array}$ & $\begin{array}{c}\text { Floor } \\
\text { area }\left(\mathrm{m}^{2}\right)\end{array}$ & $\begin{array}{c}\text { Heating } \\
\text { type }\end{array}$ & $\begin{array}{c}\text { Secondary } \\
\text { heating }\end{array}$ & $\begin{array}{c}\text { Boiler } \\
\text { efficiency }\end{array}$ \\
\hline 4 & Detached & $\begin{array}{l}\text { Solid wall with cavity } \\
\text { wall extension }\end{array}$ & $\begin{array}{c}1850-1899 \text { (ext. } \\
1996-2002)\end{array}$ & 231.1 & \multirow{11}{*}{$\begin{array}{l}\text { Gas-fired } \\
\text { water } \\
\text { central } \\
\text { heating } \\
\text { system } \\
\text { with } \\
\text { radiators }\end{array}$} & $\begin{array}{l}\text { Open-fire wood- } \\
\text { stove }\end{array}$ & 0.910 \\
\hline 7 & Detached & Cavity wall & $1965-1974$ & 93.8 & & - & 0.895 \\
\hline 8 & Detached & Cavity wall & $1965-1974$ & 104.2 & & $\begin{array}{l}\text { Gas fired in two } \\
\text { rooms }\end{array}$ & 0.650 \\
\hline 9 & Detached & $\begin{array}{l}\text { Solid wall with cavity } \\
\text { wall extension }\end{array}$ & $\begin{array}{l}1919-1944 \text { (ext. } \\
\text { post 2002) }\end{array}$ & 134.7 & & Electric fire & 0.890 \\
\hline 10 & Detached & $\begin{array}{l}\text { Solid wall with cavity } \\
\text { wall extension }\end{array}$ & $\begin{array}{l}\text { 1919-1944 (ext. } \\
\text { unknown) }\end{array}$ & 108.3 & & Gas fired & 0.886 \\
\hline 11 & Detached & Cavity wall & $1945-1964$ & 112.9 & & Gas fired & 0.888 \\
\hline 13 & Detached & Cavity wall & Post 2002 & 197.6 & & Gas fired & 0.795 \\
\hline 15 & Semi-Detached & Cavity wall & $1965-1974$ & 78.1 & & $\begin{array}{l}\text { Open-fire wood- } \\
\text { stove }\end{array}$ & 0.890 \\
\hline 17 & Detached & Cavity wall & $1965-1974$ & 108.9 & & Gas fired & 0.800 \\
\hline 18 & Detached & $\begin{array}{l}\text { Cavity wall (extension } \\
\text { too) }\end{array}$ & $\begin{array}{c}1965-1974 \text { (ext. } \\
1981-1990)\end{array}$ & 138.6 & & Gas fired & 0.800 \\
\hline 19 & Semi-Detached & Cavity wall & $1945-1964$ & 104.1 & & $\begin{array}{l}\text { Open-fire wood- } \\
\text { stove }\end{array}$ & 0.800 \\
\hline
\end{tabular}

a The boiler efficiency for each dwelling was identified using the boiler product code collected during the building survey stage and through the Building Research Establishment's (BRE) Product Characteristics Database 


\section{$213 \quad 3.2$ Sensor measurements}

214 Table 2 summarises the measured operational data and provides details on the time intervals and

215 equipment used. A combination of Hobo pendant UA-001-64 and Hobo U12-012 sensors

216 manufactured by Onset were used to capture the indoor air temperature. The sensors were placed

217 in each room between waist and head height, away from obstacles, direct solar radiation, currents

218 and heat sources, when possible, and logged air temperatures at $15 \mathrm{~min}$ or $30 \mathrm{~min}$ intervals. The

219 sensors had a measurement resolution of $0.03^{\circ} \mathrm{C}$, were accurate to $\pm 0.35^{\circ} \mathrm{C}$ and a measurement

220 range or between 0 to $50^{\circ} \mathrm{C}$. Calibration prior to the installation and post study checks of a sub-

221 sample of the sensors found the sensors to be accurate within $\pm 0.4^{\circ} \mathrm{C}$. Gas consumption was also

222 recorded. For more details on the gas monitoring process see [44].

223 Electricity consumption was recorded at the meter level in each of the participating houses. For

224 this, Current Cost transmitters and EnviR monitor were used to transmit 6-second measurements of

225 whole house electricity consumption. More information regarding the electricity consumption

226 monitoring at the meter, and at the appliance level, can be found in [47].

227 For the external air temperature and solar irradiance, weather station measurements were used. The 228 weather station was located within $3 \mathrm{~km}$ of the homes under study.

\begin{tabular}{|c|c|c|c|}
\hline Monitoring of: & Equipment used: & Interval & Positioning: \\
\hline Indoor air temperature $\left({ }^{\circ} \mathrm{C}\right)$ & $\begin{array}{l}\text { HOBO U12 / HOBO } \\
\text { Pendants }\end{array}$ & $\begin{array}{l}30 \mathrm{~min} / \\
15 \mathrm{~min}\end{array}$ & $\begin{array}{l}\text { One in each room including hallways, } \\
\text { landings, conservatories and utility rooms }\end{array}$ \\
\hline Whole-house gas consumption $\left(\mathrm{m}^{3}\right)$ & Automated meter reader & $30 \mathrm{~min}$ & $\begin{array}{l}\text { Whole-house cumulative measurements at } \\
\text { meter level }\end{array}$ \\
\hline Whole-house electricity consumption (W) & $\begin{array}{l}\text { CurrentCost transmitter } \\
\text { and EnviR monitor }\end{array}$ & $6 \mathrm{sec}$ & $\begin{array}{l}\text { Whole-house cumulative measurements at } \\
\text { meter level }\end{array}$ \\
\hline $\begin{array}{l}\text { Weather data including external air } \\
\text { temperature }\left({ }^{\circ} \mathrm{C}\right) \text { and solar radiation }\left(\mathrm{kW} / \mathrm{m}^{2}\right)\end{array}$ & 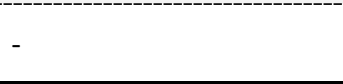 & $15 \mathrm{~min}$ & $\begin{array}{l}\text { Campus weather station, within } 3 \mathrm{~km} \text { of the } \\
\text { dwellings }\end{array}$ \\
\hline
\end{tabular}

Table 2 Summary of data collection, specifications and details

\section{Calculation of model parameters}

231 An analytical approach has been used, to determine the plausible parameter values based on

232 building physics methods. Table 3 summarises the initial estimates for the model parameters as

233 calculated using information collected through the building survey and the methodologies described

234 below. 


\begin{tabular}{|c|c|c|c|c|c|c|c|c|c|c|}
\hline \multicolumn{2}{|c|}{ Parameter } & \multirow{2}{*}{$\begin{array}{c}\mathbf{C}_{\mathbf{i}} \\
14598\end{array}$} & \multirow{2}{*}{$\frac{C_{e}}{24160}$} & \multirow{2}{*}{$\begin{array}{c}\mathbf{R e}_{\mathbf{e}} \\
0.01013\end{array}$} & \multirow[t]{2}{*}{$\theta$} & \multirow{2}{*}{$\begin{array}{c}\mathbf{R}_{\mathbf{i e}} \\
0.0076\end{array}$} & \multirow{2}{*}{$\begin{array}{c}\mathbf{R}_{\text {ea }} \\
0.00253\end{array}$} & \multirow{2}{*}{$\begin{array}{c}\mathbf{R}_{\mathbf{i a}} \\
0.009\end{array}$} & \multirow{2}{*}{$\frac{\mathbf{N}}{0.962}$} & \multirow{2}{*}{$\frac{\mathbf{A}_{\mathrm{w}}}{11.324}$} \\
\hline & 4 & & & & & & & & & \\
\hline & 7 & 6391 & 4442 & 0.0232 & & 0.0174 & 0.0058 & 0.01907 & 1.337 & 6.049 \\
\hline & 8 & 8322 & 4639 & 0.0221 & & 0.01657 & 0.00552 & 0.01259 & 1.34 & 5.084 \\
\hline & 9 & 12048 & 5311 & 0.00284 & & 0.00213 & 0.00071 & 0.01463 & 1.211 & 10.127 \\
\hline & 10 & 8760 & 5039 & 0.00443 & & 0.00332 & 0.00111 & 0.00637 & 1.478 & 13.623 \\
\hline \multirow[t]{6}{*}{ House } & 11 & 8373 & 5206 & 0.01815 & 0.75 & 0.01361 & 0.00454 & 0.01791 & 1.478 & 5.657 \\
\hline & 13 & 13867 & 7966 & 0.01652 & & 0.01239 & 0.00413 & 0.0094 & 0.959 & 7.177 \\
\hline & 15 & 5567 & 3781 & 0.03449 & & 0.02587 & 0.00862 & 0.02032 & 1.372 & 5.309 \\
\hline & 17 & 7465 & 5197 & 0.00469 & & 0.00351 & 0.00117 & 0.02432 & 1.415 & 5.157 \\
\hline & 18 & 10385 & 5642 & 0.01728 & & 0.01296 & 0.00432 & 0.02006 & 1.524 & 5.635 \\
\hline & 19 & 7659 & 4739 & 0.02043 & & 0.01532 & 0.00511 & 0.01419 & 1.524 & 9.116 \\
\hline
\end{tabular}

236 A simplified method proposed in BS EN ISO 6946:2017 [48] was used for determining the U-

237 values and, therefore, the resistance ' $\mathrm{R}_{\mathrm{e}}$ ' and ' $\mathrm{R}_{\mathrm{ia}}$ ' of the building elements. The Combined Method 238 was used for the calculation of the U-values and CIBSE Guide A [49] was used for the calculation 239 of $\mathrm{R}$.

240 A method was identified for the calculation of the positioning of the envelope node within the 241 building envelope structure when a single node representation of the building envelope is used. This

242 was needed to calculate the values of resistance between the envelope node and the indoor and 243 external air nodes, ' $R_{\mathrm{ie}}$ ' and ' $\mathrm{R}_{\mathrm{ea}}$ ', from the initially calculated ' $\mathrm{R}_{\mathrm{e}}$ ' value. It is expressed by the 244 following equations [16]:

$$
\begin{gathered}
R_{k}^{*}=\sum_{i=1}^{k-1}\left(\mathrm{R}_{i}+\frac{R_{k}}{2}\right) \\
\theta=1-\left(\frac{\sum_{k=1}^{n} \mathrm{C}_{k} R_{k}^{*}}{C_{e} R_{e}}\right) \\
\mathrm{R}_{i e}=\theta R_{e} \\
\mathrm{R}_{e a}=(1-\theta) R_{e}
\end{gathered}
$$

245 where ' $R_{k}$ ' is the resistance between the middle of layer $k$ of the construction and the external air $246\left(\mathrm{~m}^{2} \mathrm{~K} / \mathrm{W}\right),{ }^{\prime} \mathrm{R}_{\mathrm{k}}$ ' is the resistance of the layer $\mathrm{k}$ of the construction $\left(\mathrm{m}^{2} \mathrm{~K} / \mathrm{W}\right),{ }^{\text {' }} \mathrm{R}_{\mathrm{i}}$ ' is the resistance 247 between layer $\mathrm{k}$ of the construction and the external air $\left(\mathrm{m}^{2} \mathrm{~K} / \mathrm{W}\right), \mathrm{R}_{\mathrm{e}}$ is the total resistance of the 
248 building envelope $\left(\mathrm{m}^{2} \mathrm{~K} / \mathrm{W}\right),{ }^{\prime} \mathrm{C}_{\mathrm{e}}$ ' is the total capacitance of the envelope $(\mathrm{Wh} / \mathrm{K})$, ' $\mathrm{C}_{\mathrm{k}}$ ' is the 249 capacitance of the layer $\mathrm{k}(\mathrm{Wh} / \mathrm{K})$, ' $\mathrm{R}_{\text {ea }}$ ' is the resistance between the envelope node and the indoor 250 air node $\left(\mathrm{m}^{2} \mathrm{~K} / \mathrm{W}\right)$ and ' $\mathrm{R}_{\mathrm{ie}}$ ' is the resistance between the envelope node and the external air node $251\left(\mathrm{~m}^{2} \mathrm{~K} / \mathrm{W}\right)$. Due to the uncertainty regarding the different layers of the building envelope 252 components, the same node positioning was assumed for the different houses. Accordingly, a * , 253 value of 0.75 as calculated for a standard wall construction was used in this study as the initial value 254 for all houses (Table 3).

255 The heat capacitance was calculated as the summation of the capacitances of each assumed layer 256 based on the proportion of element volume they occupy. The thermal properties for each of the 257 layers were sourced from the respective tables of CIBSE Guide A [49].

258 The method provided in the UK Standard Assessment Procedure 2012 for calculating the solar 259 gains for openings was used. The average solar irradiance at a horizontal plane $\left(\mathrm{W} / \mathrm{m}^{2}\right)$ was adjusted 260 by a factor of 0.9 representing the ratio of typical transmittance to that at a normal incidence and a 261 factor of 0.76 for the total solar transmittance of the glazing at normal incidence $g_{\perp}$ (unitless). The 262 opening area ' $\mathrm{A}$ ' $\left(\mathrm{m}^{2}\right)$ for the building as measured was also adjusted using a frame factor FF of

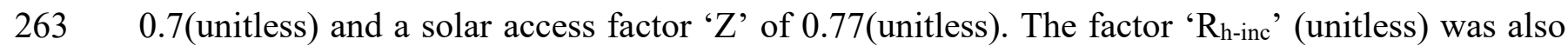
264 calculated for each window and used to convert from horizontal to vertical solar flux for the 8-week 265 period under consideration and this was also incorporated in the calculation of the effective window 266 area for solar gains, ' $\mathrm{A}_{\mathrm{w}}$ '. The resulting equation for ' $\mathrm{A}_{\mathrm{w}}$ ' is given below [50]:

$$
A_{w}=0.9 \cdot A \cdot R_{h-i n c} \cdot g_{\perp} \cdot F F \cdot Z
$$

267 For the calculation of the infiltration rates the Standard Assessment Procedure 2012 [50] 268 methodology was used allowing for shelter and wind corrections.

269 According to Table 4.21 from CIBSE Guide A [49] infiltration rates ' $N$ ' for two storey dwellings 270 can range from $0.15 \mathrm{ac} / \mathrm{h}$ in very airtight constructions and up to $1.00 \mathrm{ac} / \mathrm{h}$ in very leaky houses. Since 271 there were no specific infiltration data collected during the building survey stage the initial values 272 for ' $N$ ' were assumed to lie within the acceptable range mentioned above, with values varying 
273 depending on the dwelling's age band. To calculate the heat losses due to infiltration the equation

274 below has been used [51]:

$$
Q_{i}=\mathrm{c}_{p} \cdot \rho \cdot \frac{\mathrm{N}}{3600} \cdot \mathrm{V} \cdot \Delta \mathrm{T}_{t}
$$

275 where ' $\mathrm{Q}_{\mathrm{i}}$ ' is the heat loss due to infiltration (W), ' $\mathrm{c}_{\mathrm{p}}$ ' is the air specific heat capacity $(1000 \mathrm{~J} / \mathrm{kg} / K)$,

276 '!' is the air density $\left(1.2 \mathrm{~kg} / \mathrm{m}^{3}\right),{ }^{\prime} \mathrm{N}$ ' is the number of air changes per hour due to infiltration $(\mathrm{ac} / \mathrm{h})$,

277 ' $\mathrm{V}$ ' is the volume of the air inside the building $\left(\mathrm{m}^{3}\right)$ and ' ${ }^{\circ} \mathrm{t}_{\mathrm{t}}$ ' is the difference between external 278 and indoor air temperatures $(\mathrm{K})$.

\section{Model calibration methods, uncertainty and validation}

\section{$280 \quad 5.1$ Goodness of fit}

281 To assess how closely to the measured data the model predicts, the goodness of fit of the model was evaluDWHGXV LQJ WK UHHPHW ULFV L W K HPHDQ\$i,PRQ'X(PCR lacross the 8-week time-

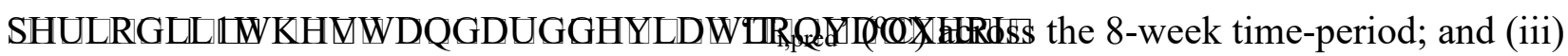
RMSE, the root mean square error between the predicted by the model values of indoor temperature, ' $\mathrm{T}_{\mathrm{i}, \text { pred }}\left({ }^{\circ} \mathrm{C}\right)$ and the measurements for indoor air temperature, ' $\mathrm{T}_{\mathrm{i}, \text { meas }}\left({ }^{\circ} \mathrm{C}\right)$.

\section{$286 \quad 5.2$ Parametric analysis}

287 Differential parametric analysis on a One-parameter-At-a-Time (OAT) [52] basis was used to 288 identify the parameters that are most influential on the model's thermal behaviour, by assessing the 289 impact that changes in each model parameter can have on the model outputs, i.e. the indoor air 290 temperature ' $\mathrm{T}_{\mathrm{i}, \text { pred' }}$ and the building envelope temperature ' $\mathrm{T}_{\mathrm{e}}$ '. Local sensitivity analysis was 291 chosen as it is a simple approach, with easily interpretable results and low computational costs [53].

292 This type of analysis is justified as it is able to identify clusters of parameters with significant impact 293 on the model outputs, where the absolute ranking of parameters in terms of significance is not of 294 the outmost importance [52], which was the requirement for this work.

295 The exploration began with the expected model parameter values as calculated using analytical 296 methods. Each parameter value was then modified. In the case of the capacitances, ' $\mathrm{C}_{\mathrm{i}}$ ' and ' $\mathrm{C}_{\mathrm{e}}$ ', 
297 the resistances, ' $\mathrm{R}_{\mathrm{e}}$ ' and ' $\mathrm{R}_{\mathrm{ia}}$ ', the infiltration rate and the opening area for solar gains, ' $\mathrm{A}_{\mathrm{w}}$ ', the 298 value was varied within a range of $-75 \%$ and $+75 \%$ of its original value. In the case of the boiler

299 efficiency 'a' and the envelope node positioning ' ', a different approach was selected, as subjecting 300 the parameters to the same relative variation of $-75 \%$ and $+75 \%$ would have led to unrealistic, not 301 physically interpretable values for the parameters. For example, varying the boiler efficiency base 302 value of 0.65 by $+75 \%$ would have resulted in a value of $1.14(>1)$, a non-plausible value for heating 303 systems installed in domestic buildings such as the houses explored. Exploring the same deviation 304 across all variables would have resulted in a more uniform parametric analysis, however, 305 maintaining results that are physically interpretable was a priority for this work. To ensure that a 306 range of realistic values was examined, a set of values was selected instead ( 0.65 to 0.95 for ' $a$ ' and 3070.30 to 0.90 for ' '). Where appropriate these values were informed by data collected through the 308 building surveys (Table 1). Finally, the percentile change in the model's output ' $\mathrm{T}_{\mathrm{i}, \text { pred }}$ ' mean, 309 standard deviation and RMSE values when compared to using the base value for each parameter 310 and the alternative values explored were calculated.

\section{$311 \quad 5.3$ Ordinary Least Squares calibration}

312 The Ordinary Least Squares (OLS) method was used to calibrate the models. According to the 313 method of least squares model of best-fit is considered the one that minimises the sum of the squares 314 of the residuals (i.e. Sum of Squared Error, SSE) [54]:

$$
\sum_{i=1}^{n} e_{i}^{2}
$$

315 where $e_{i}$ is the difference between the dependent variable's calculated value using the model and 316 the measured operational data at each time step i. For this to be achieved the necessary condition 317 for each of the parameters is [54]:

$$
\frac{\partial \sum_{i=1}^{n} e_{i}^{2}}{\partial \text { par }}=0
$$

318 The Generalised Reduced Gradient algorithm in MS Excel was selected to minimise the Error Sum 319 of Squares (SSE) at a 0.0001 precision. 
320 Constraints were established for each model parameter, to ensure that calibration to the measured 321 data was achieved, whilst maintaining parameter values that were physically plausible and 322 interpretable. As shown in Table 4, in selecting the model constraints to be used in conjunction with 323 the OLS parameter estimation technique, the empirical values of model parameter uncertainty from 324 [55] were used. In addition, findings from the parametric analysis were used, to establish whether 325 varying a specific parameter was expected to significantly impact the model output and to inform 326 the decision of allowing the respective parameter to vary during the OLS estimation or not.

\begin{tabular}{cccc}
\hline Parameter & $\begin{array}{c}\text { Empirical values of } \\
\text { parameter uncertainty }\end{array}$ & $\begin{array}{c}\text { Impact on main } \\
\text { model output }\end{array}$ & $\begin{array}{c}\text { Parameter allowed } \\
\text { to vary }\end{array}$ \\
\hline $\mathbf{C}_{\mathbf{i}}$ & $12.25 \%$ & High on variance & Yes \\
$\mathbf{C}_{\mathbf{e}}$ & $12.25 \%$ & Very low & No \\
$\mathbf{R}_{\mathbf{e}}$ & $30-40 \%$ & High on mean & Yes \\
$\mathbf{R}_{\mathbf{i a}}$ & $30-40 \%$ & High on mean & Yes \\
$\mathbf{a c} / \mathbf{h}$ & $33.33 \%$ & High on mean & Yes \\
$\mathbf{A}_{\mathbf{w}}$ & N/A & High on mean & Yes \\
$\mathbf{a}$ & N/A & Medium on mean & Yes \\
$\boldsymbol{\theta}$ & N/A & Very low & No \\
\hline${ }^{1}$ Impact on main model output has been assessed through the parametric analysis of section 6.2
\end{tabular}

Table 4 Parameter constraints used during constrained optimisation

\section{$328 \quad 5.4$ Model validation}

329 In this work, the selected model was validated through application to the dwelling sample (11

330 houses) and comparison with measured data. In addition, the model was validated through 331 comparison of its performance (in terms of resulting RMSE values) against results reported from

332 similar, fairly recent explorations of the technique for an experimental, test building [34]. Results 333 of significance of model parameter values on model output have also been validated, through 334 comparison with studies performing similar sensitivity analyses on Lumped Parameter models [53] 335 and other building energy modelling techniques [52].

\section{Results}

\section{$337 \quad 6.1$ Results using parameter estimates based on building physics}

338 The model was found to both over and under predict across the sample of houses (Figure 2). The 339 worst fit was seen in Houses 7 and 19 with constant overpredictions and only a few instances when 340 the model was able to calculate temperatures that related more clearly to the measured air 
341 temperatures. The mean predicted temperature varied between $16.34^{\circ} \mathrm{C}$ in House 17 and $21.96^{\circ} \mathrm{C}$

342 in House 18. The difference in mean air temperature between the measured and predicted ranged

343 from $0.08^{\circ} \mathrm{C}$ in House 18 and $1.43^{\circ} \mathrm{C}$ in House 19. The highest standard deviation of $2.511^{\circ} \mathrm{C}$ was

344 seen in House 18, which presented the highest variability of values across the model output ' $\mathrm{T}_{\mathrm{i}, \text { pred' }}$.

345 The lowest standard deviation of $1.291^{\circ} \mathrm{C}$ was presented in House 19. In terms of best model fit,

346 the lowest RMSE value of 0.92 was presented in House 13 and the highest, indicating the worst

347 model fit, was 1.98 in House 10. On average for the 11 houses the difference between measured

348 and calculated mean air temperature was $0.87^{\circ} \mathrm{C}$, for the standard deviation was $0.49^{\circ} \mathrm{C}$ and the

349 average RMSE was $1.35^{\circ} \mathrm{C}$.

350 Although there was no clear indication why the model predictions deviated more significantly, the

351 model seemed to be susceptible to errors when a bigger change occurred in the model inputs. This

352 was observed more clearly in Houses 9, 15, 17 and 18, where the model started to under-predict

353 significantly towards the end of the 8-week time-period, when the external air temperature dropped 354 significantly.

355 Houses 4, 15 and 19 had secondary heating that used fuel other than gas or electricity from the 356 mains. The model presented a good fit despite the existence of secondary heating in House 4, which 357 could be an indication of secondary heating not being used regularly during the 8-week period under 358 study. In Houses 15 and 19 a less good fit to the measured data was seen, indicating that secondary 359 heating might have been used more frequently, to either partially replace the use of central heating 360 or cover additional heating needs in order to achieve thermal comfort for the occupants. Significant 361 use of secondary heating was indeed observed in House 15, whereas in House 19 this could not be 362 confirmed due to lack of data on secondary heating practices. 


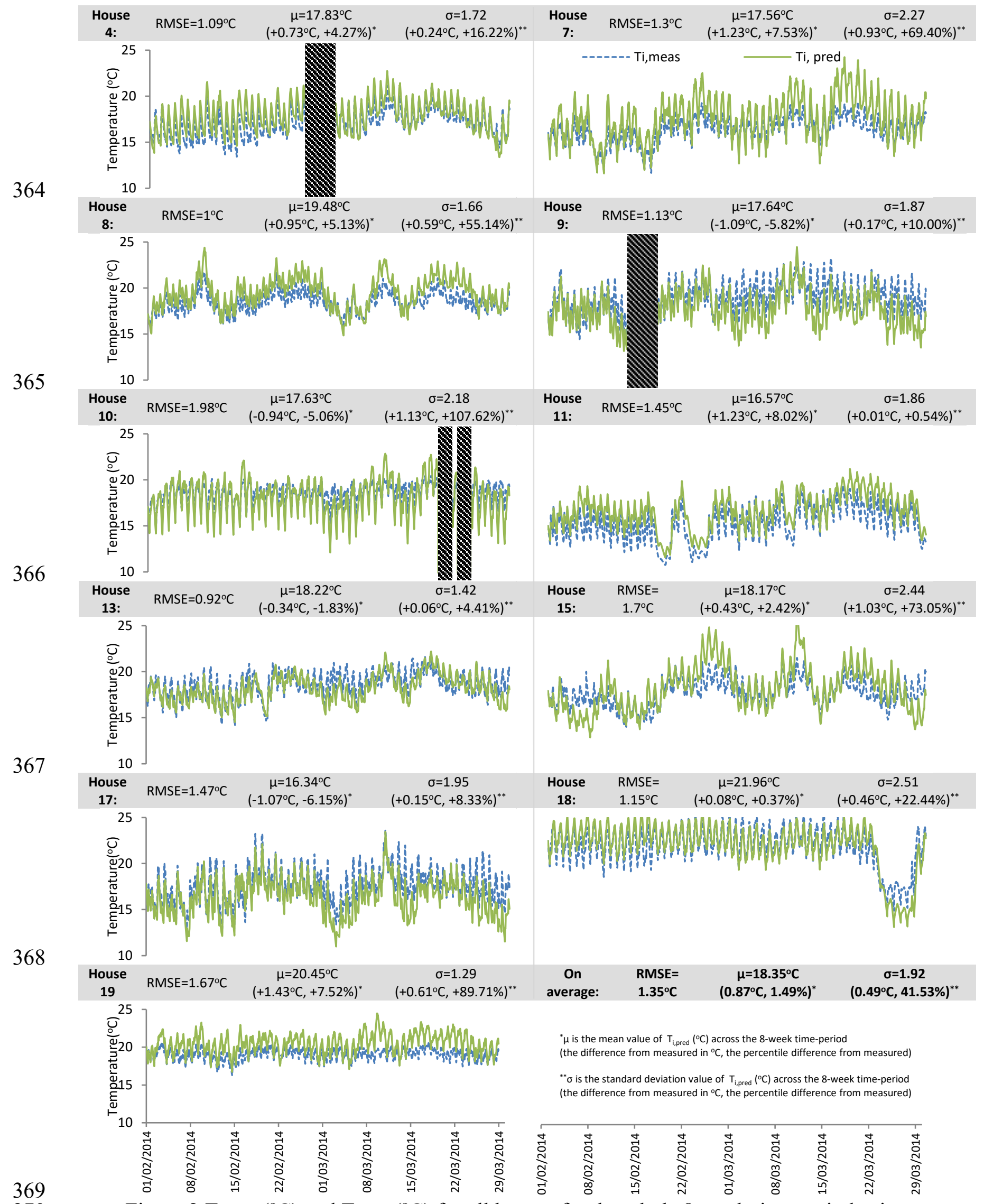

Figure $2 \mathrm{~T}_{\mathrm{i} \text {,meas }}\left({ }^{\circ} \mathrm{C}\right)$ and $\mathrm{T}_{\mathrm{i} \text {,pred }}\left({ }^{\circ} \mathrm{C}\right)$ for all houses for the whole 8-week time period using SDUDPHWHUVHVW LPDWHGXVLQJWKHEXLOGLQJVXUYHIPHWKRGWKH506(REVHUY HGW VWDQGDUGGHYLDWLRQ1RIWKHSUHGLFWHGWHPSHUDWXUHGDWDDQGWKHSHUFHQV equivalent metrics for the measured data 


\section{$374 \quad$ 6.2 Parametric analysis}

375 As shown in Table 5, consistently across the 11 houses, changes in the capacitance parameters ' $\mathrm{C}_{\mathrm{i}}$ ' and ' $\mathrm{C}_{\mathrm{e}}$ ' did not present any significant impact on the mean temperature of indoor air, with a $0.34 \%$ $0.17 \%$ and $0.28 \%-0.28 \%$ change in the mean temperature when compared to the $0 \%$ base value respectively. The resistances ' $\mathrm{R}_{\mathrm{e}}$ ' and ' $\mathrm{R}_{\mathrm{ia}}$ ' presented a more significant impact on the mean indoor air temperature with the lower resistances $(-75 \%$ from the base value) resulting in $-24.34 \%$ and $26.08 \%$ change in the mean temperature respectively and the higher resistances $(+75 \%$ from the

382 These findings are in agreement with previous work that identified the impact of U-values, which are very closely related to the resistance values, as more significant than those of thermal mass (capacitance) [52]. Variations in the window area for solar gains presented changes in the mean air temperature ranging between $-8.24 \%$ and up to $8.24 \%$. This was expected, as in a previous study focusing on assessing significance of parameters on Lumped Parameter models, window dimensions proved to belong amongst the most important parameters affecting model calculated envelope node positioning ' ' resulted in increase in the mean air temperature of $15.50 \%$ and a less significant $2.70 \%$ respectively. The highest impact on the mean air temperature resulted from changes in the infiltration rate, the boiler efficiency, the thermal resistances and the window area for solar gains. In terms of impact on the standard deviation, the internal medium capacitance ' $\mathrm{C}_{\mathrm{i}}$ ' proved to be important with a very significant change of $-30.23 \%$ for a $+75 \%$ change in the parameter's base value. This was expected as the capacitance of the building elements, the building's thermal mass, is responsible for controlling the fluctuations in temperature. Other 
400 significant parameters proved to be the window area for solar gains with an increase of $19.77 \%$ for $401 \mathrm{a}+75 \%$ change in the parameter's base value and the boiler efficiency with an increase of $12.10 \%$ 402 for a 0.95 efficiency value.

403 In terms of impact on the resulting RMSE value, influencing factors were the infiltration rate, the 404 two resistances, ' $\mathrm{R}_{\mathrm{ia}}$ ' and ' $\mathrm{R}_{\mathrm{e}}$ ', and the window area for solar gains.

405 


\begin{tabular}{|c|c|c|c|c|c|c|c|c|}
\hline \multirow{10}{*}{ 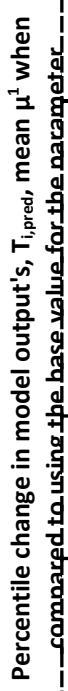 } & Percentile change in parameter: & $-75 \%$ & $-50 \%$ & $-25 \%$ & $\begin{array}{c}\text { (Base } \\
\text { value) } \\
\mathbf{0 \%} \\
\end{array}$ & $25 \%$ & $50 \%$ & $75 \%$ \\
\hline & $\mathbf{C}_{\mathbf{i}}$ & $0.34 \%$ & $0.17 \%$ & $0.06 \%$ & $0.00 \%$ & $-0.06 \%$ & $-0.11 \%$ & $-0.17 \%$ \\
\hline & $\mathbf{R}_{\mathbf{i a}}$ & $-26.08 \%$ & $-12.23 \%$ & $-4.71 \%$ & $0.00 \%$ & $3.20 \%$ & $5.55 \%$ & $7.35 \%$ \\
\hline & $\mathrm{C}_{\mathrm{e}}$ & $0.28 \%$ & $0.17 \%$ & $0.11 \%$ & $0.00 \%$ & $-0.11 \%$ & $-0.17 \%$ & $-0.28 \%$ \\
\hline & $\mathbf{R}_{\mathbf{e}}$ & $-24.34 \%$ & $-11.10 \%$ & $-4.21 \%$ & $0.00 \%$ & $2.86 \%$ & $4.88 \%$ & $6.45 \%$ \\
\hline & $A_{w}$ & $-8.24 \%$ & $-5.50 \%$ & $-2.75 \%$ & $0.00 \%$ & $2.75 \%$ & $5.50 \%$ & $8.24 \%$ \\
\hline & $\mathrm{ac} / \mathrm{h}$ & $31.80 \%$ & $18.06 \%$ & $7.85 \%$ & $0.00 \%$ & $-6.23 \%$ & $-11.33 \%$ & $-15.54 \%$ \\
\hline & $\begin{array}{l}\text { Values explored for parameter: } \\
\qquad \mathrm{a}\end{array}$ & $\begin{array}{c}\text { Base value } \\
65 \% \\
0.00 \%\end{array}$ & $\begin{array}{l}70 \% \\
2.54 \%\end{array}$ & $\begin{array}{l}75 \% \\
5.15 \%\end{array}$ & $\begin{array}{l}80 \% \\
7.75 \%\end{array}$ & $\begin{array}{c}85 \% \\
10.36 \%\end{array}$ & $\begin{array}{c}90 \% \\
12.90 \%\end{array}$ & $\begin{array}{c}95 \% \\
15.50 \%\end{array}$ \\
\hline & Values explored for parameter: & Base value 0.3 & 0.4 & 0.5 & 0.6 & 0.7 & 0.8 & 0.9 \\
\hline & $\theta$ & $0.00 \%$ & $0.75 \%$ & $1.32 \%$ & $1.84 \%$ & $2.24 \%$ & $2.53 \%$ & $2.70 \%$ \\
\hline \multirow{10}{*}{ 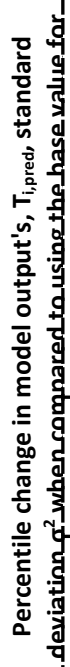 } & Percentile change in parameter: & $-75 \%$ & $-50 \%$ & $-25 \%$ & $\begin{array}{l}\text { (Base } \\
\text { value) } \\
0 \%\end{array}$ & $25 \%$ & $50 \%$ & $75 \%$ \\
\hline & $\mathbf{C}_{\mathrm{i}}$ & $190.70 \%$ & $67.44 \%$ & $22.67 \%$ & $0.00 \%$ & $-13.95 \%$ & $-23.26 \%$ & $-30.23 \%$ \\
\hline & $\mathbf{R}_{\mathbf{i a}}$ & $17.44 \%$ & $4.07 \%$ & $0.58 \%$ & $0.00 \%$ & $0.00 \%$ & $0.58 \%$ & $1.74 \%$ \\
\hline & $\mathrm{C}_{\mathrm{e}}$ & $4.07 \%$ & $2.33 \%$ & $1.16 \%$ & $0.00 \%$ & $-1.16 \%$ & $-1.74 \%$ & $-2.91 \%$ \\
\hline & $\mathbf{R}_{\mathbf{e}}$ & $12.79 \%$ & $1.74 \%$ & $0.00 \%$ & $0.00 \%$ & $0.58 \%$ & $1.16 \%$ & $1.74 \%$ \\
\hline & $A_{w}$ & $-2.33 \%$ & $-4.07 \%$ & $-2.91 \%$ & $0.00 \%$ & $4.65 \%$ & $11.63 \%$ & $19.77 \%$ \\
\hline & $\mathrm{ac} / \mathrm{h}$ & $32.56 \%$ & $10.47 \%$ & $1.74 \%$ & $0.00 \%$ & $1.16 \%$ & $3.49 \%$ & $6.40 \%$ \\
\hline & $\begin{array}{l}\text { Values explored for parameter: } \\
\qquad \mathrm{a}\end{array}$ & $\begin{array}{c}\text { Base value } \\
\quad 65 \% \\
0.00 \% \\
\end{array}$ & $\begin{array}{l}70 \% \\
0.64 \%\end{array}$ & $\begin{array}{l}75 \% \\
1.27 \%\end{array}$ & $\begin{array}{l}80 \% \\
3.18 \%\end{array}$ & $\begin{array}{l}85 \% \\
5.73 \%\end{array}$ & $\begin{array}{l}90 \% \\
8.92 \%\end{array}$ & $\begin{array}{c}95 \% \\
12.10 \%\end{array}$ \\
\hline & Values explored for parameter: & Base value 0.3 & 0.4 & 0.5 & 0.6 & 0.7 & 0.8 & 0.9 \\
\hline & $\theta$ & $0.00 \%$ & $-2.78 \%$ & $-4.44 \%$ & $-5.00 \%$ & $-5.00 \%$ & $-3.89 \%$ & $-2.22 \%$ \\
\hline \multirow{10}{*}{ 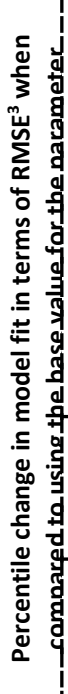 } & Percentile change in parameter: & $-75 \%$ & $-50 \%$ & $-25 \%$ & $\begin{array}{l}\text { (Base } \\
\text { value) } \\
0 \%\end{array}$ & $25 \%$ & $50 \%$ & $75 \%$ \\
\hline & $\mathbf{C}_{\mathbf{i}}$ & $141.93 \%$ & $40.88 \%$ & $10.79 \%$ & $0.00 \%$ & $-4.12 \%$ & $-5.63 \%$ & $-6.02 \%$ \\
\hline & $\mathbf{R}_{\mathbf{i a}}$ & $218.49 \%$ & $58.91 \%$ & $0.11 \%$ & $0.00 \%$ & $15.98 \%$ & $33.50 \%$ & $48.95 \%$ \\
\hline & $\mathrm{C}_{\mathrm{e}}$ & $2.57 \%$ & $1.60 \%$ & $0.75 \%$ & $0.00 \%$ & $-0.68 \%$ & $-1.30 \%$ & $-1.87 \%$ \\
\hline & $\mathbf{R e}_{\mathbf{e}}$ & $235.23 \%$ & $75.79 \%$ & $14.79 \%$ & $0.00 \%$ & $6.21 \%$ & $27.63 \%$ & $50.34 \%$ \\
\hline & $A_{w}$ & $22.06 \%$ & $3.85 \%$ & $-3.16 \%$ & $0.00 \%$ & $10.95 \%$ & $28.01 \%$ & $49.73 \%$ \\
\hline & $\mathrm{ac} / \mathrm{h}$ & $389.07 \%$ & $188.59 \%$ & $64.14 \%$ & $0.00 \%$ & $9.20 \%$ & $58.08 \%$ & $107.35 \%$ \\
\hline & Values explored for parameter: & $\begin{array}{c}\text { Base value } \\
65 \% \\
0.00 \%\end{array}$ & $\begin{array}{c}70 \% \\
-5.10 \%\end{array}$ & $\begin{array}{c}75 \% \\
-8.30 \%\end{array}$ & $-9.02 \%$ & $\begin{array}{c}85 \% \\
-6.85 \%\end{array}$ & $\begin{array}{c}90 \% \\
-2.29 \%\end{array}$ & $\begin{array}{r}95 \% \\
4.04 \%\end{array}$ \\
\hline & Values explored for parameter: & Base value 0.3 & 0.4 & 0.5 & 0.6 & 0.7 & 0.8 & 0.9 \\
\hline & $\theta$ & $0.00 \%$ & $0.29 \%$ & $1.21 \%$ & $2.44 \%$ & $3.80 \%$ & $5.21 \%$ & $6.68 \%$ \\
\hline
\end{tabular}

${ }^{1}$ The mean value calculated using the time-series of the predicted indoor air temperature, $T_{i}$, after the percentile change (of the first row) or the change of value (indicated in the second and third rows)

${ }^{2}$ The standard deviation values calculated using the time-series of $\mathrm{T}_{\mathrm{i}}$ as explained in footnote 1

${ }^{3}$ The RMSE values calculated using the time-series of $T_{i}$ as explained in footnote 1

Table 5 Average impact across all houses of changes in parameter values 


\section{$407 \quad 6.3$ Results following model calibration}

408 The final model provided results that sit in between the initial model calculations and the measured

409 data, providing a clear improvement in the initial model fit, whilst maintaining realistic values for 410 the model parameters.

411 As seen in Figure 3, in most cases, the calibrated model provided results that were closer to the 412 measured values, in terms of both mean and standard deviation. The RMSE values for the calibrated 413 model were also consistently lower than the RMSE values of the initial parameter model. By 414 varying the model parameters within acceptable limits and using the OLS technique, the gap 415 between the model output and the measurements has been substantially reduced. Similarly to the 416 initial model, the final model consistently presents higher variation than the measured values. The 417 same cannot be said for the mean air temperature for which no particular trend can be identified.

418 Looking at the final model on average for the 11 houses, a very clear improvement from the initial 419 model was seen, with the calibration lowering the average mean temperature by $0.22^{\circ} \mathrm{C}$ and 420 resulting in a very small error of $0.02^{\circ} \mathrm{C}(+0.29 \%)$ from the average mean measured temperature.

421 The best fit of the final model in terms of mean air temperature was seen in House 17, with an error 422 of $+0.04^{\circ} \mathrm{C}$ from measured mean and the worst fit in House 9, with an error of $+0.16^{\circ} \mathrm{C}$ from 423 measured mean. These results highlight the potential of the model to be used in indoor air 424 assessment applications for which the mean air temperature is an appropriate metric. Although the 425 final model offers a significantly improved representation of the variation in indoor air temperatures 426 than the initial model, a significant difference of $35.52 \%\left(0.4^{\circ} \mathrm{C}\right)$ was observed between the final 427 model and the measured data for the standard deviation, indicating that the model was less able to 428 predict the half-hourly temperature values exactly. This could be attributed to the simplified nature 429 of the model, with a single node representing the internal environment and a single node 430 representing the building envelope, and the deterministic approach followed. The average RMSE 431 across the eleven houses of the final model was $1.03^{\circ} \mathrm{C}$, showing that the model was able to estimate 432 indoor air temperatures within almost $1^{\circ} \mathrm{C}$ of accuracy on average. In all houses, the reported RMSE 
433 values sit within the range of values reported in applications of the technique in experimental 434 buildings $\left(0.33^{\circ} \mathrm{C}-1.90^{\circ} \mathrm{C}\right)[34]$, validating the model and indicating that the technique presents 435 similar performance in real houses and test buildings.

436

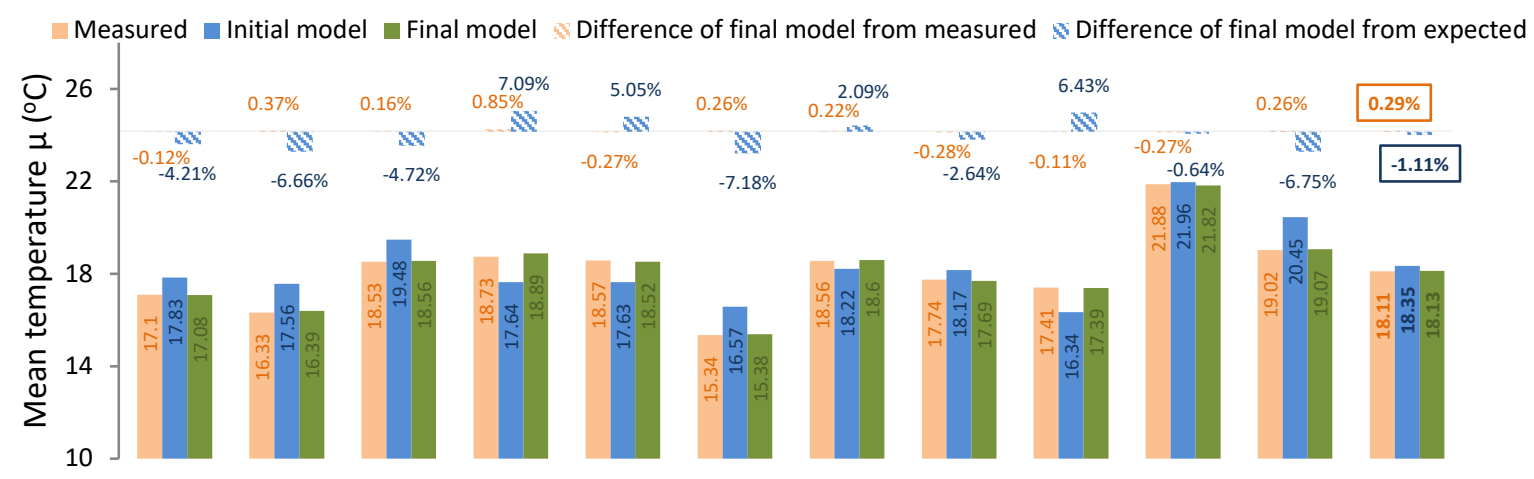

437
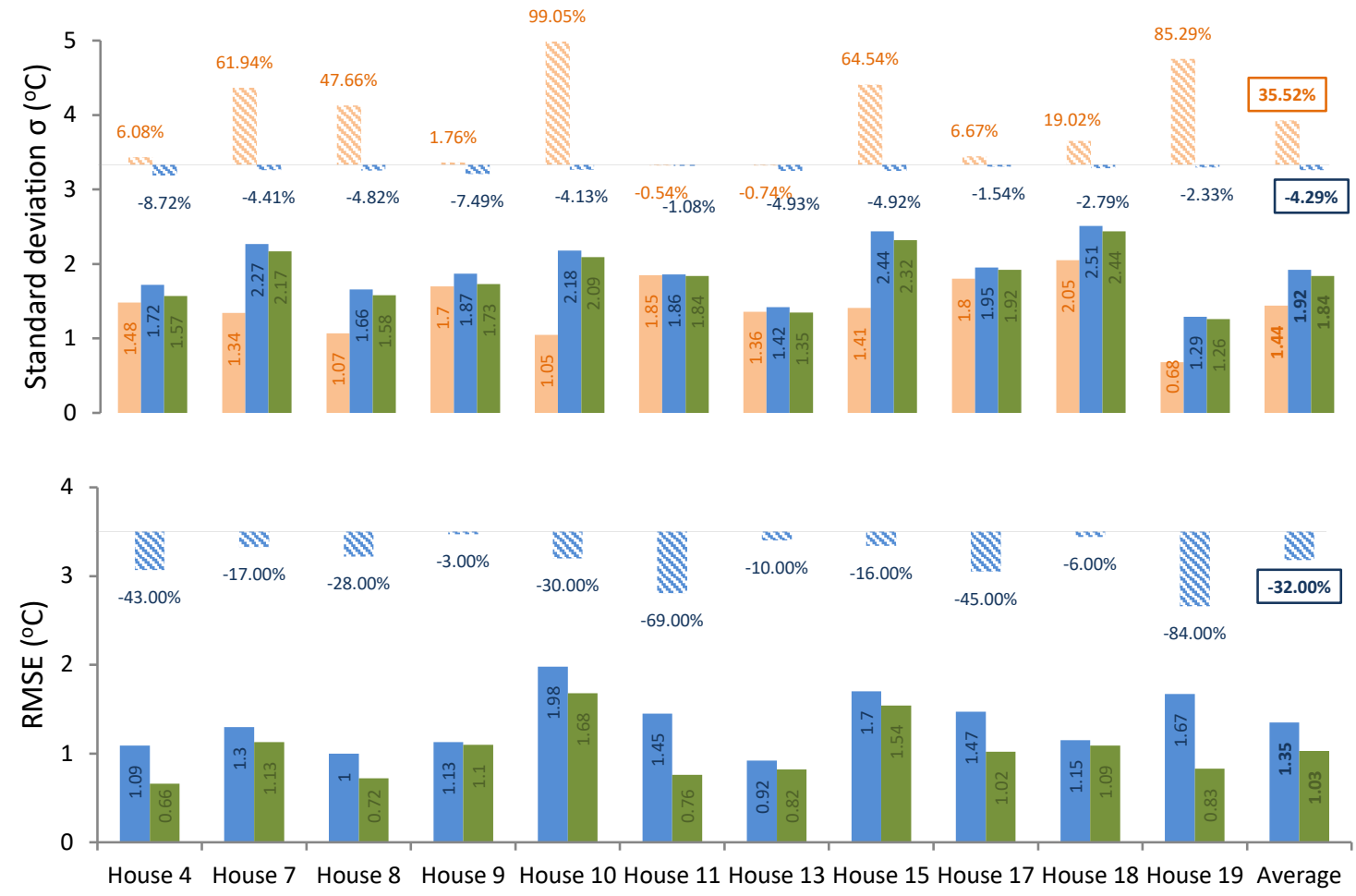

439 Figure 3 Comparison of the initial and final model fit in terms of model output mean, standard deviation and RMSE values and in terms of percentile deviation from the measured data

441 Figure 4 presents the calculated parameter values of the final model, plotted against the initial 442 parameter values. Parameters ' $\mathrm{C}$ ' ' and ' ' have not been included in the constrained OLS parameter 443 estimation, instead the expected values for the two parameters were used. From the plots it was 444 concluded that the internal medium capacitance ' $\mathrm{C}_{\mathrm{i}}$ ' was usually underestimated, reaching the upper 445 limit of allowed variance in most houses. This could be due to the effect of furniture and other 446 thermally massive objects that were inside the houses but were not taken into account when 
447 calculating the expected values for the capacitance ' $\mathrm{C}_{\mathrm{i}}$ '. No other parameter was consistently under

448 or over estimated. Most parameters varied around the expected value, as a better fit for the models

449

450
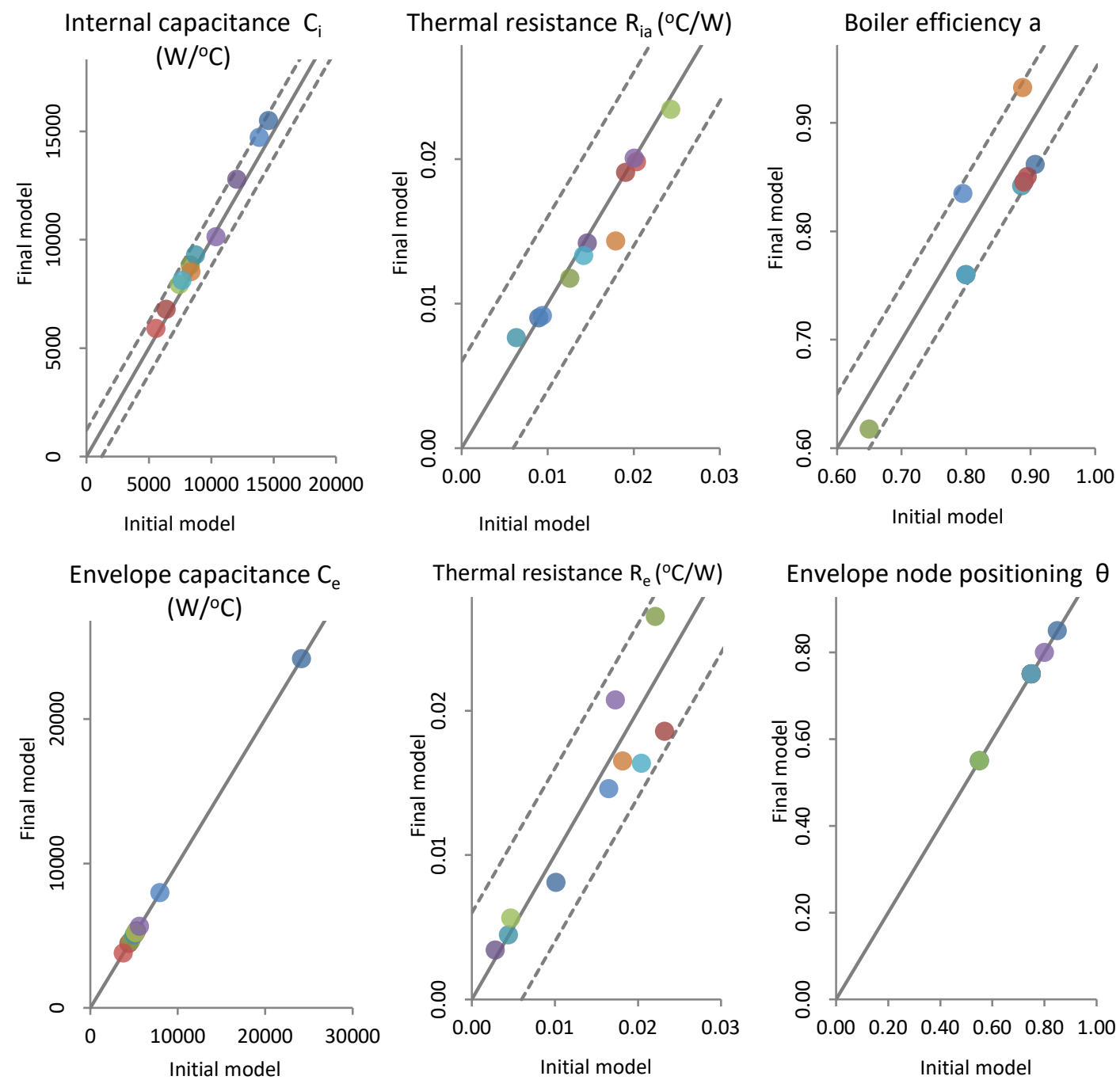

Envelope node positioning $\theta$

451
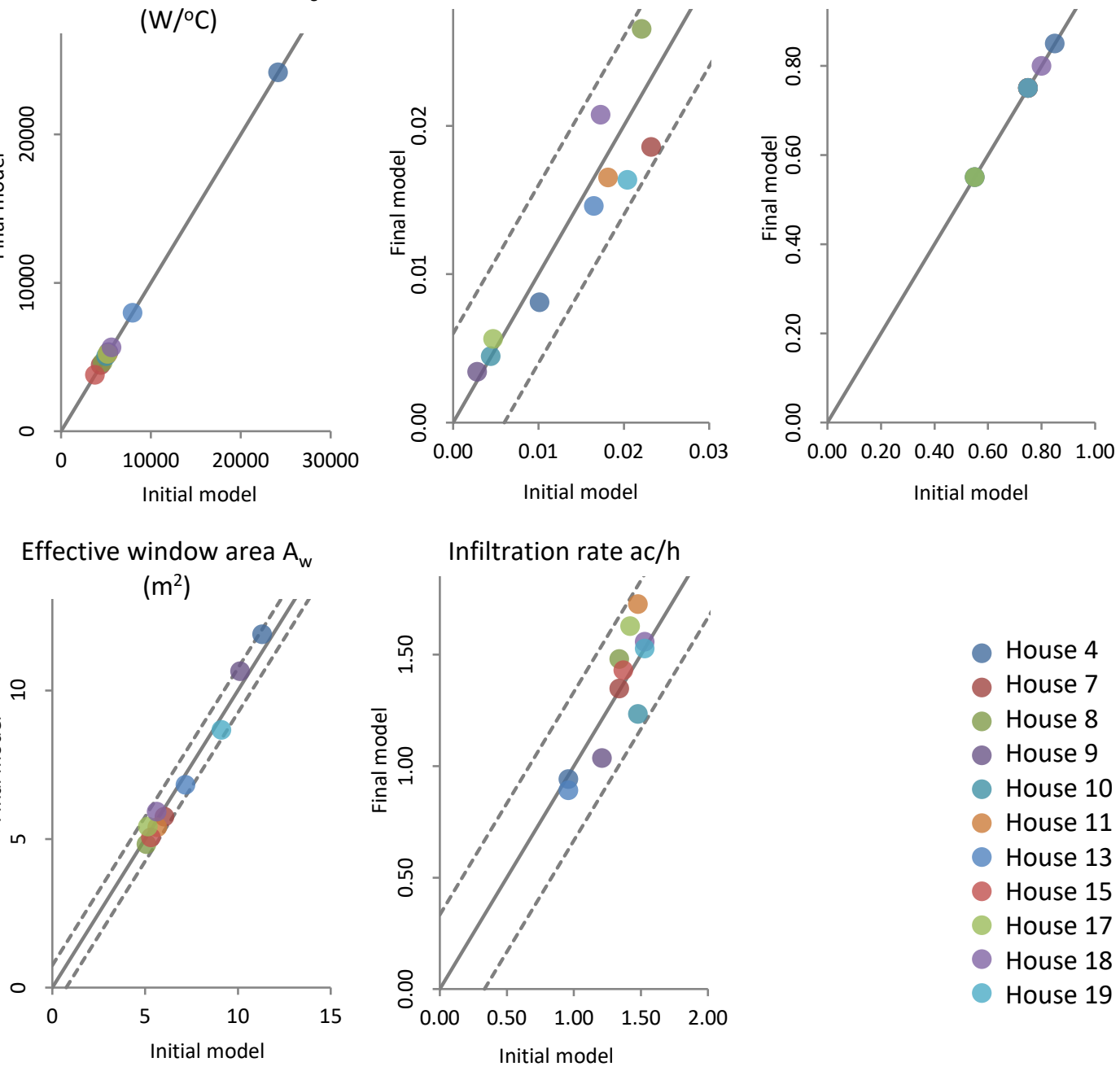

Figure 4 Initial and final model parameters across all houses 
454 was pursued. The resistance ' $\mathrm{R}_{\mathrm{ia}}$ ' was the parameter that remained closer to the expected parameter 455 values across the 11 houses. The boiler efficiency 'a' reached the upper and lower limits of

456 acceptable values, deviating significantly and consistently from the expected values, indicating that 457 an optimum value might exist outside the range of acceptable values.

\section{Discussion}

459 The selected model was based on model structures that have proven successful in previous studies.

460 Although based on previous work, the model proposed here had a new structure, with a different 461 set of parameters and inputs. Each of the model parameters related to a physical property of the 462 existing building. This model was evaluated and validated through comparison with measured data.

463 The combination of data-driven modelling with realistic parameter values is the core principle of 464 grey-box modelling, where physical interpretation of results is a requirement. One of the priorities 465 of this study was to maintain plausible and physically interpretable values for the model parameters, 466 thus ensuring that all modelling work could be related to the actual building envelope performance.

467 Throughout this work the model parameters were assessed against the expected (based on building 468 surveys and guides) values of thermal properties of the building envelope and proved relatable.

469 Local sensitivity of the selected model was performed on a-One-parameter-At-a-Time (OAT) basis, 470 to evaluate the effect of varying a single model parameter, while all other parameters maintained 471 their reference value. Local sensitivity analysis presents a simple, easily interpretable, time-efficient 472 and low-cost method. This method is able to provide insights as to which cluster of parameters 473 significantly affects the model outputs, which was the requirement for the work presented here.

474 However, there are certain limitations, with correlations between model parameters not taken into 475 consideration and uniform probability being assumed for all model parameters. Despite these 476 limitations, local sensitivity analysis methods maintain popularity in building energy modelling [56] 477 and are the first, essential step towards the identification of important parameters. Coupling of 478 parameters through global sensitivity analysis could provide further insights on model sensitivities 479 and could form part of future work. 
481 The suitability of the Lumped Parameter modelling technique to represent real-life occupied houses and the potential of using simplified grey-box methods to estimate internal temperatures have been discussed. The main conclusions from this work are:

- The calculated parameter values using analytical methods and building survey data managed to follow the reference data series quite closely in most cases, with an RMSE of $1.35^{\circ} \mathrm{C}$ on average across the 11 houses. This was achieved despite the use of total gas consumption measurements at the meter level, which did not disaggregate between space heating, domestic hot water and other uses. In addition, the existence of secondary heating in the houses seemed to affect the model fit in some cases but not consistently across the house sample, which could be an indication of intermittent use of secondary heating in the homes of the study. Even in those cases where use of secondary heating was suspected, the highest RMSE value presented was $1.7^{\circ} \mathrm{C}$, which is considered low especially given the deterministic, purely analytical approach followed for calculating the model parameters and the lack of data training in the initial model. Future monitoring studies could more carefully monitor secondary heating and further work could focus on the exploration of the modelling methods used in a non-heating season to enhance the understanding of the potential of simplified models in houses throughout the year.

- The mean value of indoor air temperature was mostly affected by the external envelope resistance ' $\mathrm{R}_{\mathrm{e}}$ ' (-24.34\% to $6.45 \%$ change in model output), the non-inertia elements (e.g. windows and doors) resistance ' $\mathrm{R}_{\mathrm{ia}}$ ' $(-26.08 \%$ to $7.35 \%$ change in model output), the window area for solar gains ' $\mathrm{A}_{\mathrm{w}}$ ' (up to $19.77 \%$ change in model output), boiler efficiency 'a' (up to $15.50 \%$ change in model output) and the infiltration rate 'ac/h' $(+31.80 \%$ for lower infiltration rates and down to $-15.54 \%$ for higher infiltration rates). The swing in the indoor air temperatures was mostly affected by the indoor air and internal elements heat capacitance ' $\mathrm{C}_{\mathrm{i}}$ ' (down to $-30.23 \%$ change in model output), highlighting the need for better 
guidance when defining and calculating this parameter. The least significant parameters in terms of goodness of model fit to the measured data proved to be the building envelope heat capacitance ' $\mathrm{C}_{\mathrm{e}}$ ' and the envelope node positioning ' '.

- Improved fit to the reference data and realistic parameter values were achieved by applying constraints to the possible parameter values, using constrained OLS, and varying all parameters apart from the building envelope capacitance and building envelope node positioning parameters, ' $\mathrm{C}_{\mathrm{e}}$ ' and ' '. On average across the eleven houses the final model presented an RMSE of $1.03^{\circ} \mathrm{C}$, which compares well to RMSE values ranging between

521 From the findings of this study, the Lumped Parameter modelling technique's potential as a non522 invasive method for assessing building performance is highlighted. The use of modelling methods 523 informed by in-situ data helps provide a realistic representation of houses in real-world settings.

524 This knowledge contributes significantly in the assessment of individual buildings, as it helps close 525 the gap between modelled and reported performance. Using models that are representative of real 526 houses, in-depth exploration for each building could help inform better control and operation 527 practices and influence behavioural changes to reduce energy consumption. The use of models 528 closely resembling real operational conditions can form the basis of more accurate forecasting 529 models of internal conditions, energy consumption and resulting $\mathrm{CO}_{2}$ emissions, with potential 530 applications in model predictive control, fault detection, energy performance and thermal comfort 531 prediction. 
532 The use of Lumped Parameter models to describe real-life domestic building systems may reduce

533 the need for extensive building surveys, resulting in a cost-effective and time-efficient approach to

534 modelling existing buildings. Readily available information, such as the information included in

535 the Energy Performance Certificates (EPCs), could also be used as a starting base to inform the

536 inputs needed to develop the models. Furthermore, it is expected that increasing amounts of

537 operational data will be collected from the homes through network connected sensors (such as smart

538 home equipment and smart meters). These data-streams could also inform the model development,

539 allowing for a non-intrusive approach to building energy modelling, by keeping the disruption of

540 the occupants to a minimum. The resulting simplified and streamlined approach provides the

541 opportunity to expand modelling from an individual building level to a wider neighbourhood or

542 urban level. Such tools could be used by research bodies and policy makers to explore retrofitting

543 and renewable energy integration scenarios, to identify best solutions for $\mathrm{CO}_{2}$ emissions reduction

544 and fuel poverty alleviation, by assessing possible impact across the nation's housing stock and 545 informing decision making at a strategic level.

\section{Acknowledgements}

548 This work has been carried out as part of the REFIT project ('Personalised Retrofit Decision

549 Support Tools for UK Homes using Smart Home Technology’, £1.5m, Grant Reference

$550 \mathrm{EP} / \mathrm{K} 002457 / 1)$. For more information see: $\underline{w w w . e p s r c . a c . u k}$ and www.refitsmarthomes.org 


\section{References}

[1] X. Li, J. Wen, Review of building energy modeling for control and operation, Renew. Sustain. Energy Rev. 37 (2014) 517-537. https://doi.org/10.1016/j.rser.2014.05.056.

[2] R.W.R. Muncey, Heat transfer calculations for buildings, Elsevier Science \& Technology, 1979. https://trove.nla.gov.au/version/11733107.

[3] A.F. Robertson, D. Gross, An electrical-analog method for transient heat-flow analysis, J. Res. Natl. Bur. Stand. (1934). 61 (1958) 105. https://doi.org/10.6028/jres.061.016.

[4] British Standards Institution, BS EN ISO 52016-1:2017 Energy performance of buildings Energy needs for heating and cooling, internal temperatures and sensible and latent heat loads, (2017) 204. https://www.iso.org/standard/65696.html.

[5] B. Dong, Z. Li, S.M.M. Rahman, R. Vega, A hybrid model approach for forecasting future residential electricity consumption, Energy Build. 117 (2016) 341-351. https://doi.org/10.1016/j.enbuild.2015.09.033.

[6] X. Xu, S. Wang, A simplified dynamic model for existing buildings using CTF and thermal network models, Int. J. Therm. Sci. 47 (2008) 1249-1262. https://doi.org/10.1016/j.ijthermalsci.2007.10.011.

[7] C. Andrade-Cabrera, D. Burke, W.J.N. Turner, D.P. Finn, Ensemble Calibration of lumped parameter retrofit building models using Particle Swarm Optimization, Energy Build. 155 (2017) 513-532. https://doi.org/10.1016/j.enbuild.2017.09.035.

[8] A. Rabl, Parameter estimation in buildings: Methods for dynamic analysis of measured energy use, J. Sol. Energy Eng. Trans. ASME. 110 (1988) 52-66. https://doi.org/10.1115/1.3268237.

[9] R. Lepore, M. Remy, E. Dumont, M. Frère, Dynamic lumped-parameter model of a heat pump designed for performance optimization, Build. Simul. 5 (2012) 233-242. https://doi.org/10.1007/s12273-012-0080-9.

[10] M. Martin, A. Afshari, P.R. Armstrong, L.K. Norford, Estimation of urban temperature and humidity using a lumped parameter model coupled with an EnergyPlus model, Energy Build. 96 (2015) 221-235. https://doi.org/10.1016/j.enbuild.2015.02.047.

[11] M. Lauster, J. Teichmann, M. Fuchs, R. Streblow, D. Mueller, Low order thermal network models for dynamic simulations of buildings on city district scale, Build. Environ. 73 (2014) 223-231. https://doi.org/10.1016/j.buildenv.2013.12.016.

[12] R. Kramer, J. van Schijndel, H. Schellen, Inverse modeling of simplified hygrothermal building models to predict and characterize indoor climates, Build. Environ. 68 (2013) 8799. https://doi.org/10.1016/j.buildenv.2013.06.001.

[13] A.K. Athieniti, M. Santamouris, Thermal analysis and design of passive solar buildings, Routledge, 2013. https://doi.org/10.4324/9781315074351.

[14] C.P. Underwood, F. Yik, Modelling methods for energy in buildings, Wiley Online Library, 2004. https://doi.org/10.1002/9780470758533.

[15] L. Laret, Contribution au developpement de modeles mathematiques du comportement thermique transitoire de structures d'habitation, Univ. Liege Fac. Des Sci. Appl. Lab. Phys. 
Du Batim. (1980).

[16] F. Lorenz, G. Masy, Méthode d'évaluation de l'économie d'énergie apportée par l'intermittence de chauffage dans les bâtiments, Trait. Par Differ. Finies d'un Model a Deux Constantes Temps, Rep. No. GM820130-01. Fac. Des Sci. Appl. Univ. Liege, Liege, Belgium. (1982).

[17] G.G.J. Achterbosch, P.P.G. de Jong, C.E. Krist-Spit, S.F. van der Meulen, J. Verberne, The development of a comvenient thermal dynamic building model, Energy Build. 8 (1985) 183-196. https://doi.org/10.1016/0378-7788(85)90003-9.

[18] A. Tindale, Third-order lumped-parameter simulation method, Build. Serv. Eng. Res. Technol. 14 (1993) 87-97. https://doi.org/10.1177/014362449301400302.

[19] J.A. Crabb, N. Murdoch, J.M. Penman, A simplified thermal response model, Build. Serv. Eng. Res. Technol. 8 (1987) 13-19. https://doi.org/10.1177/014362448700800104.

[20] J.M. Penman, Second order system identification in the thermal response of a working school, Build. Environ. 25 (1990) 105-110. https://doi.org/10.1016/0360-1323(90)90021-I.

[21] D.A. Coley, J.M. Penman, Second order system identification in the thermal response of real buildings. Paper II: Recursive formulation for on-line building energy management and control, Build. Environ. 27 (1992) 269-277. https://doi.org/10.1016/0360-1323(92)90028$\mathrm{N}$.

[22] D.A. Coley, J.M. Penman, Simplified Thermal Response Modelling in Building Energy Management. Paper III: Demonstration of a Working Controller, Build. Environ. 31 (1996) 93-97. https://doi.org/10.1016/0360-1323(95)00043-7.

[23] J.M. Schultz, S. Svendsen, Winsim: A simple simulation program for evaluating the influence of windows on heating demand and risk of overheating, Sol. Energy. 63 (1998) 251-258. https://doi.org/10.1016/S0038-092X(98)00062-0.

[24] J.H. Kämpf, D. Robinson, A simplified thermal model to support analysis of urban resource flows, Energy Build. 39 (2007) 445-453. https://doi.org/10.1016/j.enbuild.2006.09.002.

[25] T. Weber, G. Jóhannesson, An optimized RC-network for thermally activated building components, Build. Environ. 40 (2005) 1-14. https://doi.org/10.1016/j.buildenv.2004.04.012.

[26] C. Lombard, E.H. Mathews, A two-port envelope model for building heat transfer, Build. Environ. 34 (1999) 19-30. https://doi.org/10.1016/S0360-1323(97)00065-6.

[27] G. Fraisse, C. Viardot, O. Lafabrie, G. Achard, Development of a simplified and accurate building model based on electrical analogy, Energy Build. 34 (2002) 1017-1031. https://doi.org/10.1016/S0378-7788(02)00019-1.

[28] A.P. Ramallo-González, M.E. Eames, D.A. Coley, Lumped parameter models for building thermal modelling: An analytic approach to simplifying complex multi-layered constructions, Energy Build. 60 (2013) 174-184. https://doi.org/10.1016/j.enbuild.2013.01.014.

[29] C.P. Underwood, An improved lumped parameter method for building thermal modelling, Energy Build. 79 (2014) 191-201. https://doi.org/10.1016/j.enbuild.2014.05.001. 
631

[30] P. Bacher, H. Madsen, Identifying suitable models for the heat dynamics of buildings, Energy Build. 43 (2011) 1511-1522. https://doi.org/10.1016/j.enbuild.2011.02.005.

[31] H. Harb, N. Boyanov, L. Hernandez, R. Streblow, D. Müller, Development and validation of grey-box models for forecasting the thermal response of occupied buildings, Energy Build. 117 (2016) 199-207. https://doi.org/10.1016/j.enbuild.2016.02.021.

[32] J. Wang, C.Y. Tang, M.R. Brambley, L. Song, Predicting home thermal dynamics using a reduced-order model and automated real-time parameter estimation, Energy Build. 198 (2019) 305-317. https://doi.org/10.1016/j.enbuild.2019.06.002.

[33] S. Rouchier, M.J. Jiménez, S. Castaño, Sequential Monte Carlo for on-line parameter estimation of a lumped building energy model, Energy Build. 187 (2019) 86-94. https://doi.org/10.1016/j.enbuild.2019.01.045.

[34] O.M. Brastein, D.W.U. Perera, C. Pfeifer, N.O. Skeie, Parameter estimation for grey-box models of building thermal behaviour, Energy Build. 169 (2018) 58-68. https://doi.org/10.1016/j.enbuild.2018.03.057.

[35] M.M. Gouda, S. Danaher, C.P. Underwood, Building thermal model reduction using nonlinear constrained optimization, Build. Environ. 37 (2002) 1255-1265. https://doi.org/10.1016/S0360-1323(01)00121-4.

[36] J.E. Braun, N. Chaturvedi, An Inverse Gray-Box Model for Transient Building Load Prediction, HVAC\&R Res. 9669 (2002) 37-41. https://doi.org/dx.doi.org/10.1080/10789669.2002.10391290.

[37] T.R. Nielsen, Simple tool to evaluate energy demand and indoor environment in the early stages of building design, Sol. Energy. 78 (2005) 73-83. https://doi.org/10.1016/j.solener.2004.06.016.

[38] G. Reynders, J. Diriken, D. Saelens, Quality of grey-box models and identified parameters as function of the accuracy of input and observation signals, Energy Build. 82 (2014) 263274. https://doi.org/10.1016/j.enbuild.2014.07.025.

[39] D. Kim, J. Cai, K.B. Ariyur, J.E. Braun, System identification for building thermal systems under the presence of unmeasured disturbances in closed loop operation: Lumped disturbance modeling approach, Build. Environ. 107 (2016) 169-180. https://doi.org/10.1016/j.buildenv.2016.07.007.

[40] J. Vivian, A. Zarrella, G. Emmi, M. De Carli, An evaluation of the suitability of lumpedcapacitance models in calculating energy needs and thermal behaviour of buildings, Energy Build. 150 (2017) 447-465. https://doi.org/10.1016/j.enbuild.2017.06.021.

[41] E.H. Mathews, P.G. Richards, C. Lombard, A first-order thermal model for building design, Energy Build. 21 (1994) 133-145. https://doi.org/10.1016/0378-7788(94)90006-X.

[42] K. Amasyali, N.M. El-Gohary, A review of data-driven building energy consumption prediction studies, Renew. Sustain. Energy Rev. 81 (2018) 1192-1205. https://doi.org/10.1016/j.rser.2017.04.095.

[43] BEIS, Energy Consumption in the UK (ECUK) 2018, Energy Consum. UK. (2018) 1-39. https://doi.org/10.1073/pnas.1423686112. 
assessment of indirect calculation methods, Energy Build. 148 (2017) 89-105. https://doi.org/10.1016/j.enbuild.2017.04.059.

[45] S. Firth, T. Kane, V. Dimitriou, T. Hassan, F. Fouchal, M. Coleman, L. Webb, REFIT Smart Home dataset, (2017). https://doi.org/10.17028/rd.lboro.2070091.v1.

[46] DCLG, English Housing Survey: Headline Report, 2015-16, 2017.

https://assets.publishing.service.gov.uk/government/uploads/system/uploads/attachment_dat a/file/658478/2015-16_EHS_Headline_Report.pdf.

[47] D. Murray, L. Stankovic, V. Stankovic, An electrical load measurements dataset of United Kingdom households from a two-year longitudinal study, Sci. Data. 4 (2017) 1-12. https://doi.org/10.1038/sdata.2016.122.

[48] British Standards Institution, BS EN ISO 6946: 2017 - Building components and building elements - Thermal resistance and thermal transmittance - Calculation method, (2017). https://www.iso.org/standard/65708.html.

[49] CIBSE, Environmental Design CIBSE Guide A, 2016. https://doi.org/10.4324/9781315671796.

[50] Building Research Establishment, The Government's Standard Assessment Procedure for Energy Rating of Dwellings - 2012 edition, 2014. https://www.bregroup.com/sap/standardassessment-procedure-sap-2012/.

[51] F.E. Hall, Building services and equipment, Build. Serv. Equip. Vol. 1 Third Ed. (2014) 1160. https://doi.org/10.4324/9781315843537.

[52] M.H. Kristensen, S. Petersen, Choosing the appropriate sensitivity analysis method for building energy model-based investigations, Energy Build. 130 (2016) 166-176. https://doi.org/10.1016/j.enbuild.2016.08.038.

[53] G. Cattarin, L. Pagliano, F. Causone, A. Kindinis, F. Goia, S. Carlucci, C. Schlemminger, Empirical validation and local sensitivity analysis of a lumped-parameter thermal model of an outdoor test cell, Build. Environ. 130 (2018) 151-161. https://doi.org/10.1016/j.buildenv.2017.12.029.

[54] T.A. Reddy, Applied Data Analysis and Modeling for Energy Engineers and Scientists, Appl. Data Anal. Model. Energy Eng. Sci. (2011) 3. https://doi.org/10.1007/978-1-44199613-8.

[55] I.A. Macdonald, Quantifying the effects of uncertainty in building simulation, University of Strathclyde Glasgow, 2002. https://ethos.bl.uk/OrderDetails.do?uin=uk.bl.ethos.248728.

[56] T. Wei, A review of sensitivity analysis methods in building energy analysis, Renew. Sustain. Energy Rev. 20 (2013) 411-419. https://doi.org/10.1016/j.rser.2012.12.014. 